\title{
QUERCETIN REDUCES OXIDATIVE STRESS DAMAGE TO REPRODUCTIVE PROFILE INDUCED BY 2,3,7,8- TETRACHLORODIBENZO-P-DIOXIN IN MALE ALBINO RATS (RATTUS NORVEGICUS L.)
}

\author{
ABDULKAREEM, S. M. ${ }^{*}$ - NANAKALI, N. M. \\ Department of Biology, College of Education, Salahaddin University-Erbil, Erbil, Iraq \\ (phone: +964-750-478-1809) \\ *Corresponding author \\ e-mail: saman.abdulkareem@su.edu.krd; phone: +964-75-0479-4154 \\ (Received $1^{\text {st }}$ Jun 2019; accepted $2^{\text {nd }}$ Sep 2019)
}

\begin{abstract}
The article aimed to investigate the effect of the antioxidant quercetin (QCT) on male Wistar albino rats under oxidative stress caused by 2,3,7,8-tetrachlorodibenzo-p-dioxin (TCDD), focusing on their reproductive system, in order to find a way to combat declining male productivity. Thirty adult male Wistar rats of body weight ranged from 230 to $250 \mathrm{~g}$ were randomly divided into five equal groups (6 per group), designated as normal control (corn oil) and treatments: $10 \mu \mathrm{g} / \mathrm{kg}$ TCDD; $20 \mathrm{mg} / \mathrm{kg}$ QCT; $20 \mathrm{mg} / \mathrm{kg}$ QCT $+10 \mu \mathrm{g} / \mathrm{kg}$ TCDD (pretreatment of QCT) $; 10 \mu \mathrm{g} / \mathrm{kg}$ TCDD $+20 \mathrm{mg} / \mathrm{kg}$ QCT (posttreatment of QCT), and the treatments were administered intragastrically by gavage for twelve weeks and the study was conducted in Salahaddin University-Erbil, Iraq. In each group, three males were mated with untreated fertile females, and the reproductive and biochemical parameters were evaluated for each group. TCDD significantly reduced the values of sperm quality (motility, viability, and count), serum testosterone, sex ratio, body weight, gonads weight, and testicular antioxidant enzymes (superoxide dismutase, catalase, and glutathione reductase). However, increased sperm abnormality and oxidant biomarker (malondialdehyde) were observed. Concomitant treatment with QCT ameliorated these affected values, especially when QCT treatment was administered 30 min before TCDD dosing.
\end{abstract}

Keywords: $T C D D, Q C T$, sperm quality, male fertility, antioxidants

\section{Introduction}

It is believed that biological factors such as contamination of the environment have a considerable impact on male fertility. Various environmental contaminants responsible for the global decline in male reproductive health have been suggested (Erthal et al., 2018). One of these environmental polluters is dioxins, and dioxin-like compounds that are known as endocrine-disrupting and reprotoxic pollutants (Dhanabalan et al., 2011). These substances exerted their cellular and metabolic effects through interactions with the aryl hydrocarbon receptor (AhR) associated with the xenobiotic- (XRE) and antioxidant responsive (ARE) DNA elements (Nguyen et al., 2009). Upstream genes such as the promoter of the cytochrome P450 1A1 (CYP1A1) and another Ahresponsive gene that organizes the expression of the genes participating in the metabolism and detoxification of polycyclic aromatic hydrocarbons such as dioxins and dioxin like-compounds in experimental animals and humans (Mandal, 2005).

Dioxins suchlike 2,3,7,8-tetrachlorodibenzo-p-dioxin (TCDD) are leaked as unwanted by-products to the environment from several industrial processes such as the production of certain herbicides, pesticides and plastics, and combustion of plastics and medical waste (Anderson and Fisher, 2002; Hewitt et al., 2006; Lin et al., 2006). Home heating systems, cars exhaust, and cigarette smoke have been found to contain trace 
quantities of dioxin (Fiedler et al., 1990). TCDD is a toxic chemical compound and a widespread potent environmental contaminant, and because of its lipophilicity and long biological half-lives, it bioaccumulates in organisms and biomagnifies in the food web. They enter to human body primarily by eating food rich in animal fat and accumulating in human fatty tissues (Jackson et al., 2017). TCDD can affect male fertility by reducing the number of sperm (Pilsner et al., 2017), changes in motility and in sperm transit time (Sanabria et al., 2016), serum testosterone (Karman et al., 2012), lowering reproductive organs weight (Jin et al., 2010), delayed sexual maturation (Takeda et al., 2012), and can also change the "male/female" sexual ratio of offspring (You et al., 2018).

Quercetin (3,5,7,3',4'-pentahydroxyflavone, QCT), a compound of yellow powder extracted from natural sources and have a potent antioxidant, due to the existence of two pharmacophores, the catechol group in the B-ring and the $\mathrm{OH}$ group at situation 3 within the molecule scavenging the free radicals (Nabavi et al., 2015). It is found in several daily foods such as onion, grape, nuts, tea, berries, cabbage, and cauliflower (Azzi et al., 2018). Inal and Kahraman (2000) reported the following biological effects of QCT: anti-cancerous, antiviral, anti-ischemic, anti-inflammatory, and anti-allergenic, in addition to the protective power against atherosclerosis and coronary heart disease.

In animal studies, TCDD exposure has been shown to induce testicular damage and QCT may reduce the male reproductive toxicity of TCDD due to its antagonistic activity against AhR which is activated by TCDD (Ciftci et al., 2012). Melekoglu et al. (2016) reported that TCDD and related substances promote the production of reactive oxygen species (ROS) in the reproductive system. Additionally, several studies have shown that TCDD exposure results in oxidative damage to many tissues, such as the kidney, liver, and testis (Palaniswamy et al., 2014; Slezak et al., 2000).

Though to our knowledge, there are some literary works on the mitigating role of QCT in testicular damage caused by TCDD. Therefore, the purpose of this study was to assess the role of QCT in alleviating the testicular damage caused by TCDD in rats by estimating serum testosterone, sperm qualities, and determining the levels of the oxidant-antioxidant biomarkers activity in the testis.

\section{Materials and methods}

\section{Chemicals}

2,3,7,8-tetrachlorodibenzo-p-dioxin (TCDD; purity > 99\%) and quercetin (QCT; purity $>99 \%$ ) were purchased from Beijing Solarbio Science \& Technology Company, Ltd. (Beijing, China), and corn oil (Afia, Saudi Arabia) was obtained from local markets. TCDD was dissolved in corn oil at a dose of $10 \mu \mathrm{g} / \mathrm{kg}$ body weight, and QCT at a dose of $20 \mathrm{mg} / \mathrm{kg}$ body weight was also dissolved in corn oil.

\section{Experimental animals}

Thirty adult male Wistar rats, Rattus norvegicus, used for this study were procured from the Laboratory Animal Center (College of Science, University of Zakho, Duhok Province, Iraq). The rats were acclimated to the animal housing for two weeks before the start of dosing. They were preserved in plastic cages with wire mesh coverings and kept in an air-conditioned and well-ventilated room in a controlled light environment (12-h light/dark cycle) and temperature $\left(22 \pm 2{ }^{\circ} \mathrm{C}\right)$. Rats were fed on a balanced rat chow, and water (tap water) provided ad libitum. The local Committees approved the 
experimental protocols for using animals of the Salahaddin University-Erbil, Erbil city, Kurdistan Region of Iraq. The care and handling of the experimental animals were performed according to the precepts of the National Institutes of Health Guide for the Care and Use of Laboratory Animals (NRC, 2011).

\section{Experimental design}

The body weight (BW) of the animals ranged between 230 to $250 \mathrm{~g}$. After weighing, the animals randomly divided into five equal groups $(n=6)$, and the treatment was given intragastrically by gavage for twelve weeks: The $1^{\text {st }}$ group was kept as a normal group and was given corn oil (vehicle). The $2^{\text {nd }}$ group (TCDD group) was orally administered TCDD at a dose of $10 \mu \mathrm{g} / \mathrm{kg} \mathrm{BW} /$ day. A dose of $20 \mathrm{mg} / \mathrm{kg} \mathrm{BW} /$ day of QCT was treated to rats in group 3 (QCT group). In group 4 (QCT-TCDD), rats were treated with TCDD $(10 \mu \mathrm{g} / \mathrm{kg} \mathrm{BW} /$ day $)$ and QCT (20 mg/kg BW/day) $30 \mathrm{~min}$ before TCDD treatment (pre-treatment group), while in group 5 (TCDD-QCT), after $30 \mathrm{~min}$ of TCDD administration (10 $\mu \mathrm{g} / \mathrm{kg} \mathrm{BW} /$ day), animals were treated with $20 \mathrm{mg} / \mathrm{kg} \mathrm{BW} /$ day of QCT (post-treatment group).

\section{Body weight and gonadosomatic index (GSI)}

The rats weighed once per week throughout the experiment and the weight gain determined at the end of the study. The testes and cauda epididymis were removed and weighed to measure the gonado-somatic index (GSI) and epididymal-somatic index (ESI) by the following equation:

$$
\begin{gathered}
\text { GSI }=\frac{\text { Gonad weight } \times 100}{\text { Body weight }} \\
\text { ESI }=\frac{\text { Weight of epididymis } \times 100}{\text { Body weight }}
\end{gathered}
$$

\section{Serum testosterone concentration}

Serum testosterone concentration was measured by the enzyme-linked immunosorbent assay (ELISA) method using DRG ELISA testosterone kit (ELISA EIA-1559, 96 wells; DRG Instruments, GmbH, Marburg, Germany), as directed by the manufacturer's instructions.

\section{Preparation of tissue homogenates}

The testis tissue samples were homogenized in extraction solution specialized for each test, using an Ultra-Turrax (Janke and Kunkel IKA, Labortechnik, Germany) homogenizer at $20000 \mathrm{rpm} / \mathrm{min}$. The resulting homogenate was centrifuged at $8000 \mathrm{rpm}$ for $10 \mathrm{~min}$ at $4{ }^{\circ} \mathrm{C}$ using a cooling centrifuge (Biobase, China). The resulting cell-free supernatant was used for the biochemical analysis. The product was assessed spectrophotometrically according to the manufacturer's protocol.

\section{Lipid peroxidation and anti-oxidant assay}

The level of lipid peroxidation of testis tissue was measured spectrophotometrically (EMC ${ }^{2} \mathrm{GmbH}$, Germany) by determining the malondialdehyde (MDA) production and 
the antioxidant profiles such as superoxide dismutase (SOD), catalase (CAT), and glutathione reductase (GSH-R) levels were assayed using the kit method supplied by Beijing Solarbio Science \& Technology Company, Ltd, (Beijing, China). The results are expressed per unit weight of tissue.

\section{Sperm quality analysis}

Spermatozoa were obtained from the right cauda epididymis, which was carefully removed, cleaned, and immediately placed into a pre-warmed container with $1 \mathrm{ml}$ of phosphate-buffered saline (PBS, pH 7.2) at $37^{\circ} \mathrm{C}$ and minced with scissors (Narayana et al., 2005). Subsequently, sliced tissue was incubated at $37^{\circ} \mathrm{C}$ for $10 \mathrm{~min}$. All epididymal samples were examined for the following parameters:

\section{Sperm motility analysis}

Sperm motility was evaluated by counting 200 sperms per rat counted throughout at least 10 fields of view of the sample on a pre-warmed slide $\left(37^{\circ} \mathrm{C}\right)$ under prewarmed coverslip $\left(37^{\circ} \mathrm{C}\right)$ using binocular microscope (Nikon, Japan) with a warmed stage $(400 \times$ magnification).

\section{Total sperm count}

The sperm counting was carried out by diluting the sperm suspension with PBS (1:20) in the pipette with white bead, then mixed gently, after that a drop of the suspension was delivered into the Neubauer hemocytometer in each side of the counting chamber. The hemocytometer was allowed to stand for $5 \mathrm{~min}$ for sedimentation, and then sperms were counted under binocular microscope (Nikon, Japan) in large eight squares of $1 \mathrm{~mm}^{2}$ each area with the exception of the central area for erythrocyte counting of Neubauer's chamber was performed and multiplied by a 5 $\times 10^{4}$ factor to calculate the total count of spermatozoa in a million/epididymis (Narayana et al., 2005). Counting was only done for those sperms with sperm head located in squared areas.

\section{Sperm viability}

In order to determine live-dead spermatozoa, $10 \mu \mathrm{L}$ of pre-heated eosin-nigrosin stain was placed on a pre-warmed slide $\left(37^{\circ} \mathrm{C}\right)$ then $10 \mu \mathrm{L}$ of sample suspension was added and mixed gently. A smear of the sample-stain mixture was prepared and dried at room temperature. Samples were analyzed at 1000-fold magnification under a binocular microscope (Nikon, Japan). Two hundred sperms per rat were used for the determination of sperm viability. Unstained (white) sperms are viable, while stained (pink) sperms are dead sperms (Kledmanee et al., 2013).

\section{Sperm abnormality}

Sperm morphology was evaluated following smear staining with eosin-nigrosin stain. Slides were viewed with an oil immersion $(100 \times$ magnification) under a microscope (Nikon, Japan). On each slide, a total of two hundred sperms were examined for each animal, and the total sperm abnormality rates were expressed as percentages (Ciftci et al., 2012). 


\section{Fertility test}

At the end of the experiment, fertility and sex ratio was estimated in adult male rats of treated groups and the control of male counterparts. In each group, three males were randomly selected, and each one was mated with three untreated fertile females in separated plastic cages. Detection of sperm in the vaginal smear supposes an early indicator of successful mating. After five days of mixing, every three days, female rats were checked for pregnancy in three days intervals (by checking abdominal size) with calculating the pregnancy percentage for each group. Also, the number and sex ratio (male/female ratio) of newborns in each group was calculated.

\section{Statistical analysis}

Data were expressed as mean \pm standard deviation (SD) for this experiment. Analyzing of results performed by one-way analysis of variance (ANOVA) followed by Tukey's post hoc test to determine significant differences between the experimental groups using GraphPad Prism 6 version 6.01 for Windows (GraphPad Software 2012). Accepting a conventional $5 \%$ level of significance $(\mathrm{P} \leq 0.05)$, hence, all tests are statistically significant. Significant differences between treatment groups (or comparison of mean values) and appropriate vehicle control were denoted by superscript asterisks symbols *, **, ***; significant differences between TCDD group and the rest treatment groups were denoted by superscript hash symbols \#, \#\#, \#\#\#; significant differences between QCT group and the treatment groups were denoted by superscript symbols $\$, \$ \$, \$ \$ \$$ which represent significance at $\mathrm{p}<0.05, \mathrm{p}<0.01$ and $\mathrm{p}<0.001$, respectively.

\section{Results}

\section{Metabolic results}

\section{Body weight and GSI}

Results of mean $( \pm \mathrm{SD})$ body weight $(\mathrm{g})$, the GSI (\%), and the ESI (\%) are given in Table 1. There was a statistically significant decrease in body weight after twelve weeks of TCDD administration in TCDD group rats in comparison to control and QCT group rats (TCDD: $244.16 \pm 13.92 \mathrm{~g}$; Control: $294.83 \pm 7.60 \mathrm{~g} ; 286.83 \pm 8.18 \mathrm{~g}, \mathrm{p}<0.001$ ). However, co-treatment of QCT with TCDD in both QCT-TCDD and TCDD-QCT group rats reversed this effect of TCDD, but administration of QCT $30 \mathrm{~min}$ after TCDD administration was more effective than administration of QCT $30 \mathrm{~min}$ before TCDD administration (QCT-TCDD: $303.66 \pm 8.71 \mathrm{~g}$; TCDD-QCT: $320.66 \pm 10.48 \mathrm{~g}$; TCDD: $244.16 \pm 13.92 \mathrm{~g}, \mathrm{p}<0.001)$.

The GSI and ESI of the TCDD treated rat were significantly lower than that of the control rat (TCDD: $0.387 \pm 0.012 \%, 0.056 \pm 0.01 \%$; Control: $0.419 \pm 0.021 \%$, $0.075 \pm 0.01, \mathrm{p}<0.05)$. The GSI and ESI of the QCT group rats were insignificantly higher than that of the control rats $(\mathrm{p}>0.05)$ and significantly greater than that of the TCDD group ( $\mathrm{p}<0.001, \mathrm{p}<0.01)$. Rats received QCT in combination with TCDD (QCT-TCDD) significantly $(\mathrm{p}<0.001)$ reduced the adverse effects of TCDD in rats received TCDD alone, which demonstrate increasing of GSIs in comparison to TCDD group. While QCT administration in combination with TCDD (TCDD-QCT) showed a reduction in the adverse effects of TCDD compared to rats received TCDD alone, but the values did not meet any statistical significance $(\mathrm{p}>0.05)$. 
Table 1. Body weight, GSI, and ESI of control and treated groups $(n=6)$

\begin{tabular}{c|c|c|c}
\hline Groups & Body weight $(\mathbf{g})$ & GSI $(\%)$ & ESI (\%) \\
\hline Control & $294.83 \pm 7.60$ & $0.419 \pm 0.021$ & $0.075 \pm 0.010$ \\
TCDD & $244.16 \pm 13.92^{* * *}$ & $0.387 \pm 0.012^{*}$ & $0.056 \pm 0.010^{*}$ \\
QCT & $286.83 \pm 8.18^{\# \# \#}$ & $0.444 \pm 0.010^{\# \# \#}$ & $0.076 \pm 0.011^{\#}$ \\
QCT-TCDD & $303.66 \pm 8.71^{\# \#}$ & $0.427 \pm 0.029^{\# \# \#}$ & $0.065 \pm 0.005$ \\
TCDD-QCT & $320.66 \pm 10.48^{* * \# \# \$ \$ \$}$ & $0.411 \pm 0.033^{\$}$ & $0.062 \pm 0.009$ \\
\hline
\end{tabular}

\section{Testosterone concentration}

Relative to the rats of the control group, the plasma testosterone level is significantly reduced in rats administrated with TCDD, whereas the testosterone levels in rats in QCT group were not markedly changed in comparison to control rats (Control: $1.83 \pm 0.26$; TCDD: $0.31 \pm 0.19$; QCT: $2.25 \pm 0.38$, $\mathrm{p}<0.001, \mathrm{p}>0.05)$.

The results obtained in this study exhibit a significant $(\mathrm{p}<0.001)$ decrease of plasma testosterone levels in rats treated with TCDD, but in the QCT-TCDD and TCDD-QCT rats, the value of hormone testosterone is significantly reversed in the blood plasma compared to the TCDD treated group (TCDD: $0.31 \pm 0.19$; QCT-TCDD: $1.18 \pm 0.24$; TCDD-QCT: $1.01 \pm 0.18, \mathrm{p}<0.001, \mathrm{p}>0.01)$. This increase was grown, but it was still lower than the corresponding value in the blood plasma of control group. Plasma testosterone started to increase again after subsiding to approximately $1 / 6$ of the corresponding control value. In rats with QCT administered alone, the testosterone concentration was insignificantly $(\mathrm{p}>0.05)$ increased when compared with the corresponding control (Table 2).

Table 2. Testosterone hormone of control and treated groups $(n=6)$

\begin{tabular}{c|c}
\hline Groups & Testosterone concentration (ng/dl) \\
\hline Control & $1.83 \pm 0.26$ \\
TCDD & $0.31 \pm 0.19^{* * * *}$ \\
QCT & $2.25 \pm 0.38^{\# \# \#}$ \\
QCT-TCDD & $1.18 \pm 0.24^{* * \# \# \$ \$ \$ ~}$ \\
TCDD-QCT & $1.01 \pm 0.18^{* * * \# \# \$ \$ ~}$ \\
\hline
\end{tabular}

\section{Lipid peroxidation and anti-oxidant assay}

Values of the antioxidant enzymes (SOD, CAT, and GSH) and the oxidative biomarker (MDA) in the testis are shown in Table 3. A significant elevation in MDA levels was observed in the rats exposed to TCDD, whereas GSH levels, SOD, and CAT activities were meaningfully declined in testis tissues in opposition to the control group rats. Also, there were statistically insignificant changes between the QCT and control groups regarding MDA, SOD, CAT, and GSH levels. Otherwise, the decline in MDA levels and rises in SOD and CAT activities and GSH levels in the group pretreated with QCT (QCT-TCDD) were observed in comparison to the rats exposed to only TCDD. Administration of QCT 30 min after TCDD administration (post-treatment group) improved SOD, CAT, GSH, and MDA levels but these improvements (except MDA level) did not reach the statistical significance when compared with the rats of TCDD group. 


$$
-13191 \text { - }
$$

Table 3. Oxidant and antioxidant assay of control and treated groups $(n=6)$

\begin{tabular}{c|c|c|c|c}
\hline Groups & $\begin{array}{c}\text { MDA } \\
(\mathbf{n m o l} / \mathbf{g})\end{array}$ & $\begin{array}{c}\text { GSH-R } \\
(\boldsymbol{\mu g} / \mathbf{g})\end{array}$ & $\begin{array}{c}\text { SOD } \\
(\mathbf{U} / \mathbf{g})\end{array}$ & $\begin{array}{c}\text { CAT } \\
(\mathbf{U} / \mathbf{g})\end{array}$ \\
\hline Control & $22.63 \pm 7.57$ & $82.09 \pm 8.85$ & $83.32 \pm 12.39$ & $47.43 \pm 8.54$ \\
TCDD & $54.73 \pm 8.66^{* * *}$ & $39.58 \pm 9.45^{* * *}$ & $45.02 \pm 11.94^{* * *}$ & $22.95 \pm 9.18^{* * *}$ \\
QCT & $19.88 \pm 4.89^{\# \# \#}$ & $84.19 \pm 9.97^{\# \# \#}$ & $89.84 \pm 7.02^{\# \# \#}$ & $55.85 \pm 10.63^{\# \# \#}$ \\
QCT-TCDD & $34.33 \pm 10.09^{\# \# \$}$ & $56.07 \pm 9.13^{* * * * \$ \$ \$}$ & $69.64 \pm 16.66^{\#}$ & $38.25 \pm 10.33^{\# \$}$ \\
TCDD-QCT & $39.36 \pm 8.83^{* \# \$}$ & $49.33 \pm 8.03^{* * * * \$ \$}$ & $64.38 \pm 12.34^{\$}$ & $33.66 \pm 7.49^{\$ \$}$ \\
\hline
\end{tabular}

\section{Sperm analysis}

TCDD-treated rats exhibited a significant reduction in sperm count, motility, and viability percentage, while increased morphologically abnormal sperms in the TCDD group compared with the control and other experimental groups. The sperm numbers, motility, viability, and abnormality were $58.25 \times 10^{6} \pm 5.53,61.33 \pm 8.93 \%$, $51.33 \pm 6.47 \%$, and $12.83 \pm 1.94 \%$, respectively, in the TCDD group. The corresponding values in the control group were $71.33 \times 10^{6} \pm 6.96,86.33 \pm 7.28 \%, 84.50 \pm 8.33 \%$, and $6.50 \pm 1.87 \%$. However, QCT consumption by rats treated with TCDD resulted in significant (QCT-TCDD: $\mathrm{p}<0.001$, TCDD-QCT: $\mathrm{p}<0.01$ ) ameliorations in all sperm parameters when compared with the TCDD group rats. The corresponding values in the QCT-TCDD group were $67.66 \times 10^{6} \pm 5.90,78.33 \pm 8.16 \%, 69.83 \pm 5.23 \%$, and $7.16 \pm 1.47 \%$, and similar amounts in the TCDD-QCT group were $64.25 \times 10^{6} \pm 5.98$, $71.67 \pm 7.11 \%, 66.67 \pm 4.50 \%$, and $8.66 \pm 1.03 \%$, but the results showed that administration of QCT 30 min before TCDD administration was more effective than QCT administration 30 min after TCDD administration. On the other hand, the sperm number, sperm motility, sperm viability, and sperm abnormality were not significantly changed in rats orally received QCT when compared with the rats of the control group, while a considerable change was observed in comparison to TCDD group rats (Table 4).

Table 4. Sperm analysis of control and treated groups $(n=6)$

\begin{tabular}{c|c|c|c|c}
\hline Groups & $\begin{array}{c}\text { Sperm count } \\
\text { (million/epididymis) }\end{array}$ & $\begin{array}{c}\text { Sperm motility } \\
\mathbf{\%}\end{array}$ & $\begin{array}{c}\text { Sperm viability } \\
\mathbf{\%}\end{array}$ & $\begin{array}{c}\text { Sperm abnormality } \\
\mathbf{\%}\end{array}$ \\
\hline Control & $71.33 \pm 6.96$ & $86.33 \pm 7.28$ & $84.50 \pm 8.33$ & $6.50 \pm 1.87$ \\
TCDD & $58.25 \pm 5.53^{*}$ & $61.33 \pm 8.93^{* * *}$ & $51.33 \pm 6.47^{* * * *}$ & $12.83 \pm 1.94^{* * *}$ \\
QCT & $71.91 \pm 7.76^{\# \#}$ & $88.50 \pm 7.03^{\# \#}$ & $86.17 \pm 7.19^{\# \# \#}$ & $5.16 \pm 1.60^{\# \# \#}$ \\
QCT-TCDD & $67.66 \pm 5.90$ & $78.33 \pm 8.16^{\# \#}$ & $69.83 \pm 5.23^{* \# \# \# \$}$ & $7.16 \pm 1.47^{\# \#}$ \\
TCDD-QCT & $64.25 \pm 5.98$ & $71.67 \pm 7.11^{* \$}$ & $66.67 \pm 4.5^{* * \# \# \$ \$}$ & $8.66 \pm 1.03^{\# \# \$ \$}$ \\
\hline
\end{tabular}

\section{Fertility test}

The percentage of pregnant female rats in the group received TCDD was significantly lower than that of the control and QCT group (TCDD: 66.66\%; Control: 100\%; QCT: $100 \%, \mathrm{p}<0.05)$. Whereas in the QCT-TCDD and TCDD-QCT group, the pregnancy rate was reversed compared to the TCDD group, but the difference did not attend any statistical significance, and this increase grew but was remain lower than the corresponding value in the control group (QCT-TCDD: 88.88\%; TCDD-QCT: $88.88 \%$, $\mathrm{p}>0.05)$. 
The sex ratio of the control group's 9 litters ( 89 embryos), 6 litters of the TCDD group (51 embryos), 9 litters of the QCT group (92 embryos), 8 litters of the QCTTCDD group (77 embryos) and 8 litters of the TCDD-QCT group (74 embryos) was linked to the visual examination of anogenital distance away and the presence of male genitals (Table 5). Our results showed a statistically significant decrease in the sex ratio of embryos in the TCDD group against the control and QCT group rats (TCDD: $27.62 \pm 21.14 \%$; Control: $52.01 \pm 8.58 \%$; QCT: $53.98 \pm 10.26 \%, \mathrm{P}<0.05)$. In general, QCT treatment significantly increased pregnancy percentage, mean litter size, and sex ratio (male/female ratio) in comparison to TCDD treatment. Additionally, the results exhibited that QCT administration along with TCDD in both QCT-TCDD and TCDDQCT groups in contrast to TCDD group insignificantly increased pregnancy percentage, mean litter size, and sex ratio percentage. Also, there were no significant changes between QCT-TCDD and TCDD-QCT groups in means of pregnancy percentage, mean litter size, and sex ratio percentage. The QCT substance when given together with TCDD, especially in a group when pre-treated with QCT, brought pregnancy percentage, mean litter size, and sex ratio percentage closer to the control level.

Table 5. Fertility test of control and treated groups $(n=6)$

\begin{tabular}{c|c|c|c|c|c}
\hline Groups & $\begin{array}{c}\text { Pregnant } \\
\text { female rats (\%) }\end{array}$ & $\begin{array}{c}\text { Total No. of } \\
\text { male newborns }\end{array}$ & $\begin{array}{c}\text { Total No. of } \\
\text { female newborns }\end{array}$ & $\begin{array}{c}\text { Mean litter } \\
\text { size }\end{array}$ & $\begin{array}{c}\text { Total sex ratio } \\
(\%)\end{array}$ \\
\hline Control & $100 \pm 0.00$ & $46 \pm 0.78$ & $43 \pm 1.09$ & $9.88 \pm 1.05$ & $52.01 \pm 8.58$ \\
TCDD & $66.66 \pm 0.50^{*}$ & $21 \pm 1.80^{*}$ & $30 \pm 2.64$ & $5.66 \pm 4.38^{*}$ & $27.62 \pm 21.14^{*}$ \\
QCT & $100 \pm 0.00^{\#}$ & $50 \pm 1.50^{\# \#}$ & $42 \pm 1.00$ & $10.22 \pm 1.64^{\#}$ & $53.98 \pm 10.26^{\#}$ \\
QCT-TCDD & $88.88 \pm 0.33$ & $42 \pm 2.12^{\#}$ & $35 \pm 1.69$ & $8.55 \pm 3.46$ & $48.27 \pm 19.83$ \\
TCDD-QCT & $88.88 \pm 0.33$ & $38 \pm 1.92$ & $36 \pm 1.65$ & $8.22 \pm 3.30$ & $40.47 \pm 24.15$ \\
\hline
\end{tabular}

\section{Discussion}

Male reproductive disorders, such as a diminution in sperm quality and quantity, have shown an increasing trend in recent years. Several environmental/lifestyle factors (like exposure to dioxins, traffic exhaust fumes, smoking, and obesity) appear to negatively affect both the perinatal and adult testes (Sharpe, 2010; Wang et al., 2017). TCDD was found to increase oxidative stress and inhibit the activity of the antioxidant enzymes in testis and influences the serum level of testosterone hormone. It has also been reported that TCDD decelerates the progressive motility of epididymal sperm (Dhanabalan et al., 2015).

The current data showed the beneficial properties of QCT on TCDD induced reproductive impairment in male rats. We found a reduction in the sperm characteristics of TCDD treated rats compared to control rats. TCDD induced significant oxidative disorders in the testis tissue. Administration of QCT to rats received TCDD markedly decreased the reproductive damage and its oxidative stress induced by TCDD. Similarly, other researchers (Ciftci et al., 2012) found that TCDD produced oxidative stress in rat testes tissue. In addition to significantly decreasing serum testosterone levels, sperm count with its motility as well as increasing abnormal sperm percentage and testicular damages with TCDD dosing. It was thought that spermatological effects of TCDD might be due to its oxidative and histopathological effects. 
The results of the study showed that body weight in TCDD group less gained in comparison to control rats and also GSI and ESI in the rats treated with TCDD decreased. The results of the study are in agreement with previous findings obtained by Seefeld et al. (1984) and Ciftci et al. (2010). They showed that oral TCDD administration decreased body weight compared to control rats. However, Awal et al. (2001) reported that in male rats, exposure to TCDD during adulthood resulted in a reduction in the weights of testes and accessory sex organs, but it still remains unclear which cells of the testis are particularly affected by TCDD. This adverse effects of TCDD, including those related to the endocrine-disrupting activities (Le MagueresseBattistoni et al., 2017; Decherf and Demeneix, 2011). While, pre and post-treatment with QCT could improve the gonad and body weight in the rats treated with TCDD.

Furthermore, antioxidant defence systems consist of SOD, glutathione peroxidase (GPx), CAT (enzymatic), and GSH (non-enzymatic) protects the cell against oxidative damage in normal physiological conditions. TCDD treatment caused a significant increase in testicular MDA levels in the present study with a decrease in testicular SOD, GSH, and CAT activity compared to the control group. An increased MDA concentration is maybe a consequence of the reduced production of antioxidants in the TCDD treated rats' tissues thereby shifting the accurate balance in favour of ROS, thus leading to an excess of pathologic damage to sperm cells and coincident loss of function (Oyeyipo et al., 2014). The antioxidant superoxide dismutase enzyme dramatically speeds up the dismutation of the superoxide anion to hydrogen peroxide $\left(\mathrm{H}_{2} \mathrm{O}_{2}\right)$. Catalase breaks down $\mathrm{H}_{2} \mathrm{O}_{2}$ to $\mathrm{H}_{2} \mathrm{O}$ and $\mathrm{O}_{2}$, and the glutathione peroxidase/reductase system catalyzes $\mathrm{H}_{2} \mathrm{O}_{2}$ and lipid hydroperoxide degradation by reduced glutathione. Reducing the activity of SOD, CAT, GSH-R, and GPx could reflect the negative effect of TCDD on antioxidant enzymes in epididymal sperm (Latchoumycandane et al., 2003). Due to the direct damaging effect of TCDD, reduced activity of one or more antioxidant systems leads to increased lipid peroxidation and oxidative stress, resulting in testicular and sperm toxicity.

As pointed out in the introduction that TCDD binds to an AhR in the cytoplasm, the receptor complex (AhR-TCDD) translocates into the nucleus, where AhR heterodimerizes with the Ah receptor nuclear translocator (ARNT), connects to dioxinresponsive enhancer elements and regulates the transcription of target genes (Baba et al., 2005). The mechanisms of TCDD-induced disorders in the reproductive system of mammals have been shown to be multiple, including impairment of spermatogenesis (Foster et al., 2010), steroidogenesis (Adamsson et al., 2009), dropping in the number of testicular cells (Johnson et al., 1994), and induction of cytochrome P450 (CYP) 1 family enzymes, leading to inactivation of steroid hormones (Badawi et al., 2000). The treatment of QCT ameliorated these detrimental effects. These results corroborate the previous findings of Ciftci et al. (2012) and El-Gerbed et al. (2015). Ciftci et al. (2012) reported that QCT could reduce testicular damage caused by TCDD in rats. El-Gerbed et al. (2015) said that exposure to TCDD triggered semen quality to deteriorate, a reduction in fertility indexes, decreased the activity of serum enzymes, and decreased testosterone, in addition to histological changes in the tests. The team also highlighted the effect of QCT in reducing the adverse impact generated by TCDD.

Our results showed decreased male/female ratio in TCDD group rats compared with control group rats. Several studies have shown that exposure to TCDD in humans and animal reduces the male sex ratio of offspring (You et al., 2018; Mocarelli et al., 2000; Rowlands et al., 2006; Ishihara et al., 2007). James (2006) supposes that before 
conception, elevated gonadotropin and low levels of testosterone would have injured and distorted Y- bearing gametes. Song et al. (2018) found that Y chromosome-bearing human spermatozoa were more susceptible to EDCs than spermatozoa with the $\mathrm{X}$ chromosome. Ishihara et al. (2010) investigated the effects on sex ratio, sperm concentration, and motility of TCDD exposure. They found that TCDD leads to decreasing $\mathrm{Y}$-bearing/X-bearing sperm ratio. Although it is still unclear why $\mathrm{Y}$ spermatozoa are more susceptible to high TCDD levels than X spermatozoa, You et al. (2018) proposed that after exposure to stressful conditions such as endocrine-disrupting chemicals (EDCs), the fertilization capacity according to their chromosome constitution may differ. Interestingly, Y spermatozoa survived at high TCDD concentrations for a shorter time than $\mathrm{X}$ spermatozoa. Furthermore, the reduced male sex ratio of births was related to the limited lifespan of $\mathrm{Y}$ spermatozoa and they attributed that to the antiandrogenic properties in utero or during lactation in adult rats that might be exposed to dioxin-like compounds and polychlorinated biphenyls (PCBs), leading to permanently changed sperm-transit time through the epididymis and the extra-testicular excurrent duct system (Jongbloet et al., 2002).

\section{Conclusion}

In summary, that we really found that rats subjected to TCDD showed reduced sexual activity, low motility with sperm count inhibition, viability, decreased antioxidant enzymes activity, additionally increased sperm abnormality and oxidative biomarker (MDA) in testis tissue. QCT treatment could minimize the effects of TCDD in rats, in part by improving sexual performance and eliminating oxidative damage. Thus, these results suggested that QCT could be used as protective agents against reproductive toxicity induced by TCDD in male rats. Further studies are required to clarify the mechanism of QCT as a therapeutic agent against the toxic effects of TCDD.

Acknowledgements. This study was supported as a $\mathrm{PhD}$ plan by Salahaddin University-Erbil, Erbil, Kurdistan Region-Iraq (Administrative order No. 1/1/15738. Signed on December 1, 2015). The authors wish to gratefully thank Rêbwar M. Hama Salih, Sarwar N. Jafar, and Younis M. Saleh for excellent technical support performed for spermatological and biochemical tests.

\section{REFERENCES}

[1] Adamsson, A., Simanainen. U., Viluksela, M., Paranko, J., Toppari, J. (2009): The effects of 2,3,7,8-tetrachlorodibenzo-p-dioxin on foetal male rat steroidogenesis. - International Journal of Andrology 32: 575-585.

[2] Anderson, D. R., Fisher, R. (2002): Sources of dioxins in the United Kingdom: the steel industry and other sources. - Chemosphere 46: 371-381.

[3] Awal, M. A., Siddiqi, M. N. H., Kurohmaru, M., Andriana, B. B., Mizukami, T., Kanai, Y., Hayashi, Y. (2001): Biochemical effects of 2, 3, 7, 8-tetrachlorodibenzo-p-dioxin (TCDD) on the sertoli cell culture from prepubertal male Wistar rats. - Journal of Medical Sciences 1: 311-315.

[4] Azzi, J., Jraij, A., Auezova, L., Fourmentin, S., Greige-Gerges, H. (2018): Novel findings for quercetin encapsulation and preservation with cyclodextrins, liposomes, and drug-incyclodextrin-in-liposomes. - Food Hydrocolloids 81: 328-340. 
[5] Baba, T., Mimura, J., Nakamura, N., Harada, N., Yamamoto, M., Morohashi, K. I., FujiiKuriyama, Y. (2005): Intrinsic function of the aryl hydrocarbon (dioxin) receptor as a key factor in female reproduction. - Molecular and Cellular Biology 25: 10040-10051.

[6] Badawi, A. F., Cavalieri, E. L., Rogan, E. G. (2000): Effect of chlorinated hydrocarbons on expression of cytochrome P450 1A1, 1A2 and 1B1 and 2-and 4-hydroxylation of 17ßestradiol in female Sprague-Dawley rats. - Carcinogenesis 21: 1593-1599.

[7] Ciftci, O., Tanyildizi, S., Godekmerdan, A. (2010): Protective effect of curcumin on immune system and body weight gain on rats intoxicated with $2,3,7,8$ Tetrachlorodibenzo-p-dioxin (TCDD). - Immunopharmacology and Immunotoxicology 32: 99-104.

[8] Ciftci, O., Aydin, M., Ozdemir, I., Vardi, N. (2012): Quercetin prevents 2, 3, 7, 8-tetrachlorodibenzo-p-dioxin-induced testicular damage in rats. - Andrologia 44: 164173.

[9] Decherf, S., Demeneix, B. A. (2011): The obesogen hypothesis: a shift of focus from the periphery to the hypothalamus. - Journal of Toxicology and Environmental Health, Part B 14(5-7): 423-448.

[10] Dhanabalan, S., Jubendradass, R., Latha, P., Mathur, P. P. (2011): Effect of restraint stress on 2, 3, 7, 8 tetrachloro dibenzo-p-dioxin induced testicular and epididymal toxicity in rats. - Human \& Experimental Toxicology 30: 567-578.

[11] Dhanabalan, S., Mathur, P. P., Latha, P. (2015): TCDD and corticosterone on testicular steroidogenesis and antioxidant system of epididymal sperm in rats. - Toxicology and Industrial Health 31: 811-822.

[12] El-Gerbed, M. S., El-Saad, A. M. A., Haussein, A. B. (2015): 2, 3, 7, 8-tetrachlorodibenzo-p-dioxin induced testicular toxicity in rats and the protective effect of quercetin: biochemical, histopathological and immunohistochemical studies. - Journal of Applied Pharmaceutical Science 5: 099-109.

[13] Erthal, R. P., Siervo, G. E., Silveira, L. T., Scarano, W. R., Fernandes, G. S. (2018): Can resveratrol attenuate testicular damage in neonatal and adult rats exposed to 2, 3, 7, 8tetrachlorodibenzo-p-dioxin during gestation? - Reproduction, Fertility and Development 30: 442-450.

[14] Fiedler, H., Hutzinger, O., Timms, C. W. (1990): Dioxins: sources of environmental load and human exposure. - Toxicological \& Environmental Chemistry 29: 157-234.

[15] Foster, W. G., Maharaj-Briceño, S., Cyr, D. G. (2010): Dioxin-induced changes in epididymal sperm count and spermatogenesis. - Environmental Health Perspectives 118: 458-464.

[16] Inal, M. E., Kahraman, A. (2000): The protective effect of flavonol quercetin against ultraviolet a induced oxidative stress in rats. - Toxicology 154(1-3): 21-29.

[17] Ishihara, K., Warita, K., Tanida, T., Sugawara, T., Kitagawa, H., Hoshi, N. (2007): Does paternal exposure to 2, 3, 7, 8-tetrachlorodibenzo-p-dioxin (TCDD) affect the sex ratio of offspring?. - Journal of Veterinary Medical Science 69: 347-352.

[18] Ishihara, K., Ohsako, S., Tasaka, K., Harayama, H., Miyake, M., Warita, K., Tanida, T., Mitsuhashi, T., Nanmori, T., Tabuchi, Y., Yokoyama, T. (2010): When does the sex ratio of offspring of the paternal 2, 3, 7, 8-tetrachlorodibenzo-p-dioxin (TCDD) exposure decrease: in the spermatozoa stage or at fertilization? - Reproductive Toxicology 29: 6873.

[19] Jackson, E., Shoemaker, R., Larian, N., Cassis, L. (2017): Adipose tissue as a site of toxin accumulation. - Comprehensive Physiology 7: 1085-1135.

[20] James, W. H. (2006): Offspring sex ratios at birth as markers of paternal endocrine disruption. - Environmental Research 100: 77-85.

[21] Jin, M. H., Hong, C. H., Lee, H. Y., Kang, H. J., Han, S. W. (2010). Toxic effects of lactational exposure to 2, 3, 7, 8-tetrachlorodibenzo-p-dioxin (TCDD) on development of male reproductive system: Involvement of antioxidants, oxidants, and p53 protein. Environmental Toxicology: An International Journal 25: 1-8. 
[22] Johnson, L., Wilker, C. E., Safe, S. H., Scott, B., Dean, D. D., White, P. H. (1994): 2, 3, 7, 8-Tetrachlorodibenzo-p-dioxin reduces the number, size, and organelle content of Leydig cells in adult rat testes. - Toxicology 89: 49-65.

[23] Jongbloet, P. H., Roeleveld, N., Groenewoud, H. M. (2002): Where the boys aren't: Dioxin and the sex ratio. - Environmental Health Perspectives 110: 1-3.

[24] Karman, B. N., Basavarajappa, M. S., Hannon, P., Flaws, J. A. (2012): Dioxin exposure reduces the steroidogenic capacity of mouse antral follicles mainly at the level of HSD17B1 without altering atresia. - Toxicology and Applied Pharmacology 264: 1-12.

[25] Kledmanee, K., Taweedet, S., Thaijongruk, P., Chanapiwat, P., Kaeoket, K. (2013): Effect of L-cysteine on Chilled carp (Cyprinus carpio) semen qualities. - The Thai Journal of Veterinary Medicine 43: 91-97.

[26] Latchoumycandane, C., Chitra, K. C., Mathur, P. P. (2003): 2, 3, 7, 8Tetrachlorodibenzo-p-dioxin (TCDD) induces oxidative stress in the epididymis and epididymal sperm of adult rats. - Archives of Toxicology 77: 280-284.

[27] Le Magueresse-Battistoni, B., Labaronne, E., Vidal, H., Naville, D. (2017): Endocrine disrupting chemicals in mixture and obesity, diabetes and related metabolic disorders. World Journal of Biological Chemistry 8: 108-119.

[28] Lin, L. F., Lee, W. J., Chang-Chien, G. P. (2006): Emissions of polychlorinated dibenzop-dioxins and dibenzofurans from various industrial sources. - Journal of the Air \& Waste Management Association 56: 1707-1715.

[29] Mandal, P. K. (2005): Dioxin: a review of its environmental effects and its aryl hydrocarbon receptor biology. - Journal of Comparative Physiology B 175: 221-230.

[30] Mark Hewitt, L., Parrott, J. L., McMaster, M. E. (2006): A decade of research on the environmental impacts of pulp and paper mill effluents in Canada: sources and characteristics of bioactive substances. - Journal of Toxicology and Environmental Health, Part B 9: 341-356.

[31] Melekoglu, R., Ciftci, O., Cetin, A., Basak, N., Celik, E. (2016): The beneficial effects of Montelukast against 2, 3, 7, 8-tetrachlorodibenzo-p-dioxin toxicity in female reproductive system in rats. - Acta Cirurgica Brasileira 31: 557-563.

[32] Mocarelli, P., Gerthoux, P. M., Ferrari, E., Patterson Jr, D. G., Kieszak, S. M., Brambilla, P., Vincoli, N., Signorini, S., Tramacere, P., Carreri, V., Sampson, E. J. (2000): Paternal concentrations of dioxin and sex ratio of offspring. - Lancet 355: 1858-1863.

[33] Nabavi, S. F., Russo, G. L., Daglia, M., Nabavi, S. M. (2015): Role of quercetin as an alternative for obesity treatment: You are what you eat! - Food Chemistry 179: 305-310.

[34] Narayana, K., Prashanthi, N., Nayanatara, A., Kumar, H. H. C., Abhilash, K., Bairy, K. L. (2005): Effects of methyl parathion (o, o-dimethyl o-4-nitrophenyl phosphorothioate) on rat sperm morphology and sperm count, but not fertility, are associated with decreased ascorbic acid level in the testis. - Mutation Research/Genetic Toxicology and Environmental Mutagenesis 588: 28-34.

[35] Nguyen, T., Nioi, P., Pickett, C. B. (2009): The Nrf2-antioxidant response element signaling pathway and its activation by oxidative stress. - Journal of Biological Chemistry 284: 13291-13295.

[36] NRC (2011): Guide for the Care and Use of Laboratory Animals. 8th ed. - National Research Council, National Academies Press, Washington, DC. https://www.ncbi.nlm.nih.gov/books/NBK54050/.

[37] Oyeyipo, I. P., Raji, Y., Bolarinwa, A. F. (2014): Antioxidant profile changes in reproductive tissues of rats treated with nicotine. - Journal of Human Reproductive Sciences 7: 41-46.

[38] Palaniswamy, K. S., Vishwanadha, V. P., Singaravelu, S. R. (2014): Fish oil rich in eicosapentaenoic acid protects against oxidative stress-related renal dysfunction induced by TCDD in Wistar rats. - Cell Stress and Chaperones 19: 409-419. 
[39] Pilsner, J. R., Parker, M., Sergeyev, O., Suvorov, A. (2017): Spermatogenesis disruption by dioxins: epigenetic reprograming and windows of susceptibility. - Reproductive Toxicology 69: 221-229.

[40] Rowlands, J. C., Budinsky, R. A., Aylward, L. L., Faqi, A. S., Carney, E. W. (2006): Sex ratio of the offspring of Sprague-Dawley rats exposed to 2, 3, 7, 8-tetrachlorodibenzo-pdioxin (TCDD) in utero and lactationally in a three-generation study. - Toxicology and applied Pharmacology 216: 29-33.

[41] Sanabria, M., Cucielo, M. S., Guerra, M. T., dos Santos Borges, C., Banzato, T. P., Perobelli, J. E., Leite, G. A. A., Anselmo-Franci, J. A., Kempinas, W. D. G. (2016): Sperm quality and fertility in rats after prenatal exposure to low doses of TCDD: A threegeneration study. - Reproductive Toxicology 65: 29-38.

[42] Seefeld, M. D., Keesey, R. E., Peterson, R. E. (1984): Body weight regulation in rats treated with 2, 3, 7, 8-tetrachlorodibenzo-p-dioxin. - Toxicology and Applied Pharmacology 76: 526-536.

[43] Sharpe, R. M. (2010): Environmental/lifestyle effects on spermatogenesis. Philosophical Transactions of the Royal Society B: Biological Sciences 365: 1697-1712.

[44] Slezak, B. P., Hatch, G. E., DeVito, M. J., Diliberto, J. J., Slade, R., Crissman, K., Hassoun, E., Birnbaum, L. S. (2000): Oxidative stress in female B6C3F1 mice following acute and subchronic exposure to 2, 3, 7, 8-tetrachlorodibenzo-p-dioxin (TCDD). Toxicological Sciences 54: 390-398.

[45] Song, W. H., Mohamed, E. A., Pang, W. K., Kang, K. H., Ryu, D. Y., Rahman, M. S., Pang, M. G. (2018): Effect of endocrine disruptors on the ratio of X and Y chromosomebearing live spermatozoa. - Reproductive Toxicology 82: 10-17.

[46] Takeda, T., Fujii, M., Taura, J., Ishii, Y., Yamada, H. (2012): Dioxin silences gonadotropin expression in perinatal pups by inducing histone deacetylases a new insight into the mechanism for the imprinting of sexual immaturity by dioxin. - Journal of Biological Chemistry 287: 18440-18450.

[47] Wang, C. Y., Cui, J. T., Lu, Z. L., Ma, X. L., Wang, J. H., Sun, Y. C. (2017): Effects of aroclor 1254 on the DNA methylation of imprinted genes in the adult mouse sperm. Applied Ecology and Environmental Research 15: 999-1012.

[48] You, Y. A., Mohamed, E. A., Rahman, M. S., Kwon, W. S., Song, W. H., Ryu, B. Y., Pang, M. G. (2018): 2, 3, 7, 8-Tetrachlorodibenzo-p-dioxin can alter the sex ratio of embryos with decreased viability of Y spermatozoa in mice. - Reproductive Toxicology 77: 130-136. 